\title{
Valoración económica de los servicios ecosistémicos de una Laguna del sudeste bonaerense (Argentina)
}

\author{
Economic evaluation of ecosystem services in a Lagoon \\ in the south-eastern part of the Buenos Aires state, Argentina
}

\author{
Agustina Iwan ${ }^{1}$ \\ E. Marcela Guerrero ${ }^{2}$ (i) \\ Asunción Romanelli ${ }^{3}$ \\ Emilia Bocanegra ${ }^{4}$
}

\section{Resumen}

La valoración de servicios ecosistémicos es un tema ampliamente debatido y en constante producción. En Argentina existe poca evidencia empírica de aplicación de metodologías tendientes a dar valor económico a los beneficios asociados a ecosistemas específicos.

Este trabajo explica la situación ambiental de una laguna endorreica en el sudeste de la provincia de Buenos Aires y la valoración económica de algunos servicios ecosistémicos asociados a ella.

La Laguna de Los Padres es un humedal de importancia local debido a los servicios ecosistémicos que proporciona y como espacio recreativo de valor simbólico sociocultural para la población.

La modelización por su carácter sintético y capacidad explicativa, permitió caracterizar el sistema y la selección de cuatro servicios ecosistémicos (SE) posibles de ser valorados física y crematísticamente considerando la disponibilidad de información. Los mimos son: el abastecimiento de agua, el secuestro de $\mathrm{CO}_{2}$, el control de la erosión y el valor de existencia de la biodiversidad.

La valoración económica casi siempre infra o subvalora el ambiente; no obstante, puede ser un instrumento político útil para la toma de decisiones de planificación y gestión ambiental en general porque lleva la discusión al terreno monetario.

La sumatoria de los servicios ambientales permitió aproximar un Valor Económico Total (VET) equivalente al 4,6\% del presupuesto anual 2014 del Partido de Gral. Pueyrredón con una superficie de $1.453,44 \mathrm{~km}^{2}$, y 619.000 habitantes (Instituto de Estadísticas y Censos [INDEC], 2010).

Palabras clave: Humedales; economía ecológica; modelo ecosistémico; valoración de servicios ecosistémicos.

1 Centro de Investigaciones y Estudios Ambientales (CINEA). FCH Universidad Nacional del Centro de la Provincia de Buenos Aires, Argentina. agustina.iwan@gmail.com

2 Centro de Investigaciones y Estudios Ambientales (CINEA). FCH Universidad Nacional del Centro de la Provincia de Buenos Aires, Argentina.emarguerr@gmail.com

3 Instituto de Investigaciones Marinas y Costeras (IIMyC). Consejo Nacional de Investigaciones Científicas y Técnicas (CONICET)UNMdP. Mar del Plata, Argentina e Instituto de Geología de Costas y del Cuaternario-CONICET, Universidad Nacional de Mar del Plata (UNMdP)-CIC, FCEyN, Mar del Plata, Argentina. aromanel@mdp.edu.ar

4 Instituto de Geología de Costas y del Cuaternario. Universidad Nacional de Mar del Plata (UNMdP)-CIC-FCEyN, Argentina. ebocaneg@ mdp.edu.ar 


\begin{abstract}
The evaluation of ecosystem services is a widely debated subject, one which is in constant production. In Argentina there is little empirical evidence about the use of methodologies that tend to give economic value to the benefits associated with specific ecosystems.

This paper explains the environmental situation of an endorheic lagoon in the southeast of the province of Buenos Aires and the economic valuation of some ecosystem services associated with it.

Laguna de Los Padres is a major local wetland because of the ecosystem services it provides and also it is a recreational area of symbolic sociocultural value for the community.

Modelling, because of its synthetic character and explanatory capacity, helps distinguish the system and the selection of four ecosystem services (SE): water supply, CO2 sequestration, soil erosion and the existing value of biodiversity. Considering the availability of information, the physical and economical aspects of this service can be evaluated.

Economic valuation generally undervalues the environment; however, it can be a useful policy tool for environmental planning and management decisions because it brings the discussion to the monetary level.

General Pueyrredón is a municipality that covers an area of 1,453.44 km2 and 619,000 inhabitants (Institute of Statistics and Censuses [INDEC], 2010).

The sum of the environmental services considered helps estimate the Total Economic Value (TEV) that is equivalent to $4.6 \%$ of the 2014 annual Municipal budget.
\end{abstract}

Keywords: Wetlands; Ecological economics; Ecosystem model; Valuation of ecosystem services.

\title{
1. Introducción
}

Los humedales son ecosistemas con altas tasas de productividad y diversidad biológica que proveen bienes y servicios de interés tanto hidrológico, ecológico, económico como social -en general denominados servicios ecosistémicos (SE) (de Groot, Alkemade, Braat, Hein, y Willemen, 2010). No obstante, esos beneficios ambientales son ignorados o subvalorados y no considerados en la toma de decisiones. Esta es una de las causas del deterioro y pérdida de los humedales en el mundo (Pascual et al., 2014; Newcome, Provins, Johns, Ozdemiroglu y Ghazoul, 2005). En gran medida la falta de interés responde al desconocimiento de los beneficios de los ecosistemas, y a que no poseen una utilidad individual expresada a través de un precio ${ }^{5}$ que los haga bienes económicos.

No obstante, desde hace unas décadas ha crecido el interés científico-académico por cuantificar, evaluar y valorar aquellos beneficios ecosistémicos provistos por la naturaleza y derivados de procesos ecológicos que permiten el mantenimiento de las condiciones necesarias para el desarrollo de los sistemas humanos (Millennium Ecosystem Assessment [MEA] 2005; De Groot Op. Cit., Barbier, Acreman, Knowler, 1997; Barbier, 2011; Oteros Rozas, Martín López, González y Montes, 2010; Pérez Bustamante y Sterling, 2010).

En general los SE hacen referencia al conjunto de beneficios que la sociedad obtiene de los ecosistemas, en forma de bienes materiales (materias primas, alimento, energía fósil, etc.), servicios en sentido estricto (regulación del clima, regulación de la composición atmosférica, formación de suelos, control de procesos hidrológicos, mantenimiento de recursos genéticos, etc.) o incluso de otros beneficios menos tangibles como los culturales, religiosos o espirituales (Daily, 1997; MEA, 2005; Daniel et al. 2012).

Desde MEA se han propuesto diversidad de tipologías sobre SE (Haines-Young \& Potschin, 2010; Daniel et al. 2012; Luederitz et al. 2015; Hermelingmeir \& Nicholas, 2017). Es probable que las tipologías continúen evolucionando, porque como señala Costanza (2008) es posible considerar otras formas de categorización más allá del listado que sugiere MEA o Wallace (2007). Es más, tal pluralidad de enfoques puede constituirse en un desafío para el intercambio y el dialogo sobre el tema.

5 La mayoría de los servicios ecosistémicos son bienes públicos sin precio. La valoración de SE propone la creación de mercados artificiales (Boyd y Banzhaf, 2007). Una forma común es calcular el valor crematístico del SE en forma indirecta a través de la disponibilidad a aceptar o a pagar por la conservación de ese bien. No obstante, existe cierto acuerdo que el Estado debe establecer las reglas de la inclusión en el mercado de estos bienes a través de sus políticas (Pérez Bustamante y Sterling, 2010). 
Identificar y valorar crematísticamente los SE puede constituir una herramienta poderosa para instalar a los humedales en las agendas de conservación, ya que permite cuantificar los beneficios (tanto los que entran en el mercado como los que no) que las personas obtienen de los servicios de estos ecosistemas; así como ser un elemento de peso en la toma de decisiones sobre la conservación de sistemas provisores de servicios vitales para la sociedad (Feria Toribio y Ramos, 2009).

En el sudeste bonaerense existen numerosas lagunas que proporcionan importantes SE como el aporte de nutrientes a los ciclos geoquímicos, la regulación local y regional del clima, la regulación de flujos hidrológicos, ser soporte de especies, ofrecer oportunidades educativas, recreativas, riqueza paisajística y valores simbólicos, entre otros. No obstante, estos cuerpos de agua, muchas veces son receptores de los efectos negativos de ciertas actividades humanas. Más importante considerando que los humedales, son frágiles y muestran una elevada vulnerabilidad frente a impactos no siempre evidentes o reversibles (Grosman, 2008). Las lagunas en particular, ligadas a la dinámica hídrica subterránea, muestran una debilidad añadida, la evolución de los niveles piezométricos, que son dependientes a su vez del régimen de recarga al acuífero y de la explotación que se hace de él (Aguilera y Murillo, 2009).

Se considera la Laguna de los Padres cita en el Sistema de Tandilia (Fig. 1). Esta posee una red de drenaje bien definida con arroyos de escasa expresión topográfica ${ }^{6}$, que descienden de las sierras en dos vertientes, norte y sur. Se trata de un cuerpo de agua de régimen permanente y somero con una superficie de $2.97 \mathrm{~km}^{2}$ y una profundidad media de $1.24 \mathrm{~m}$ (Pozzobon \& Tell, 1995). Recibe un único afluente, el Arroyo de Los Padres y drena parte de sus aguas superficiales a través del Arroyo de La Tapera.

Figura 1. Cuenca del Arroyo y Laguna de Los Padres, Buenos Aires, Argentina

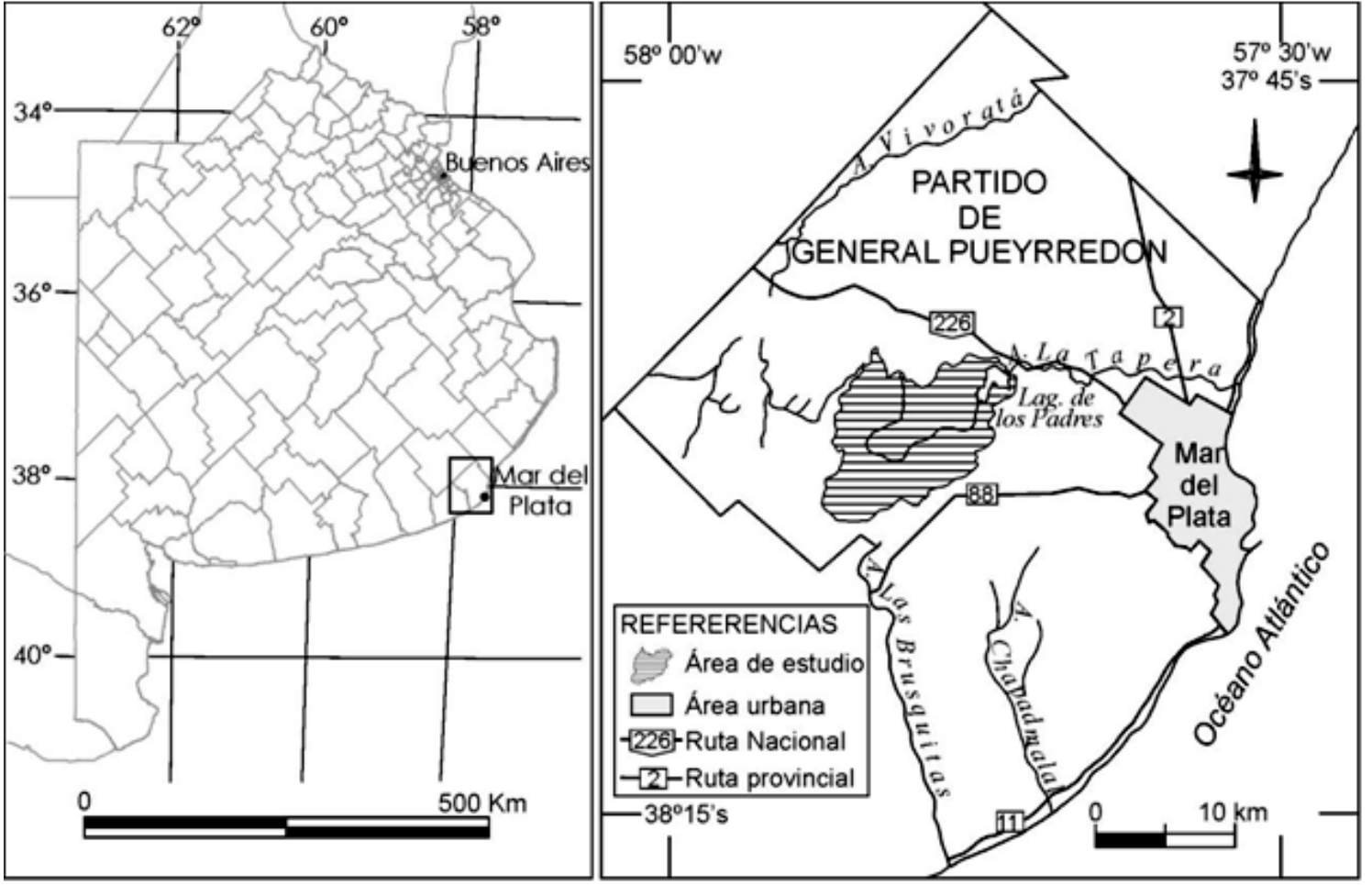

Fuente: Del Río, et al., 1992.

El modelo hidrogeológico conceptual establece una relación efluente - influente con el acuífero, recibiendo un importante aporte subterráneo de las zonas topográficamente más altas y, a su vez, drenando subterráneamente un volumen significativo aguas abajo (Cionchi, et al., 1982).

Posee clima "templado con influencias oceánicas", con un continuo intercambio de masas de aire en la interfase tierra-mar (SMN 1961-1990), y una temperatura media anual entre los años 1961-1990 fue

6 Es decir que por su caudal (itinerante y escaso) no han generado valles profundos en la geomorfología de las sierras que atraviesan 
de $14^{\circ} \mathrm{C}$. Se trata de un área protegida municipal que en 2011 fue declarada "Reserva Natural de Objetivo Definido Educativo" (Decreto provincial 469/11).

La figura 2 muestra la laguna y da cuenta de una zona litoral extensa y desarrollada, en la que el junco Schoenoplectus californicus (C.A. Meyer) Soják es la especie dominante, ocupando actualmente el 96\% de su línea de costa y alcanzando mayor cobertura en las zonas de ingreso y egreso de agua (Esquius, Escalante y Solari, 2008). Es un área de conservación nacional de la especie curro (Colletiaparadoxa) que junto con el tala constituyen los únicos representantes vegetales autóctonos (dentro del estrato arbustivo-arbóreo) que aún se conservan en la región (Del Río, et al., 2007).

Figura 2. Vistas de la laguna
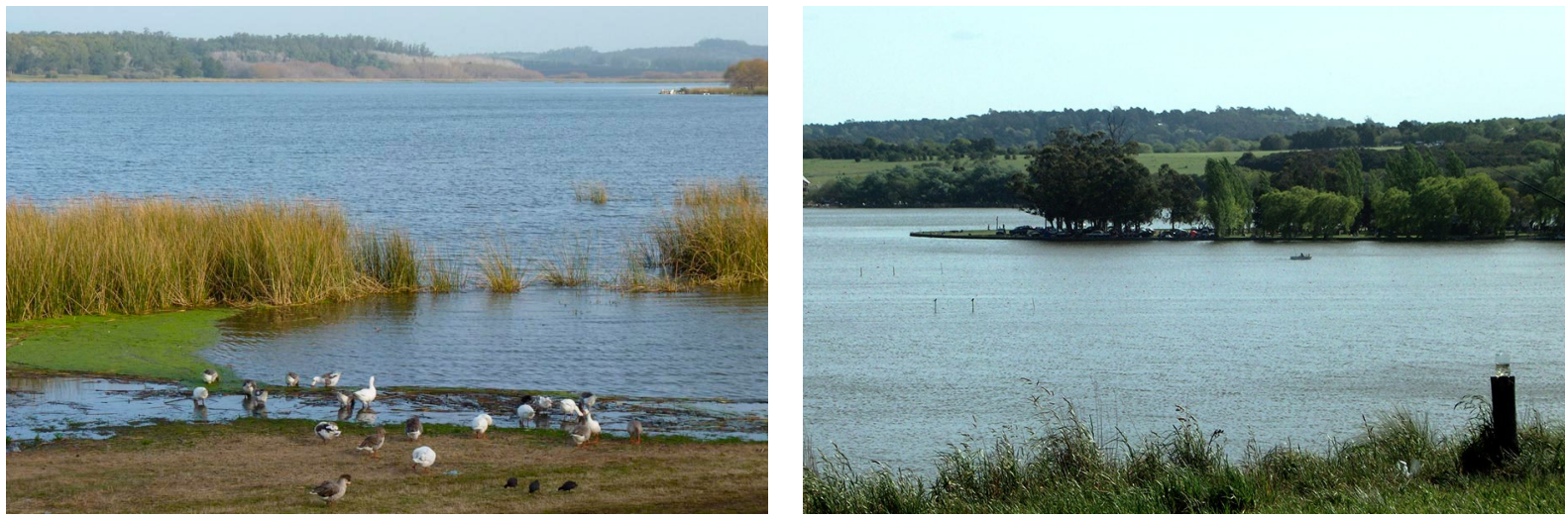

Fuente: Iwan, 2015

Entre las actividades humanas que más impactan el ambiente natural bajo de estudio se destacan acciones como la extracción del agua subterránea, el drenaje de aguas superficiales y el aporte de aguas urbanas lo cual en su conjunto se traduce en una modificación del ciclo hidrológico (Romanelli, Lima, Londoño, Martínez y Massone, 2012).

Los montes cultivados para el uso recreativo, constituidos por vegetación leñosa, ocupan el área que bordea la laguna: pinos, cipreses, acacias, sauces y álamos entre otros. Asociados a los cuerpos de agua se desarrollan juncales, pajonales de totora. Entre la vegetación acuática se encuentra la gambarrusa (Alternanthera philoxeroides) y la cola de zorro (Cortaderia selloana). La fauna es diversa y abundante. Existen más de ciento veinte especies de aves relacionadas con el ambiente acuático (Frangi, 1975; Cabrera 1976; Bellagamba, 1997; Romanelli y Massone, 2011).

Como no toda la superficie de la laguna es área protegida provincial, en la cuenca coexisten otros usos entre los que se destacan: asentamientos urbanos, explotaciones agrícola-ganaderas extensivas e intensivas -como la frutihortícola- y espacios de conservación (Bó et al. 2009; Romanelli et al. 2012). La figura 3 permite ver la diversidad e intensidad de usos de suelos alrededor de la laguna.

El área de reserva posee infraestructura recreativa de clubes de pesca, recreos y restaurantes, con constante afluencia de turistas y visitantes. En una zona inmediata a la laguna se localiza el cinturón hortícola de Mar del Plata, un espacio de uso intensivo con prácticas de manejo que incluyen el uso de fertilizantes orgánicos e inorgánicos (Baccaro et al. 2006). Las producciones incluyen hortalizas, frutillas y plantas ornamentales. Al este de la laguna, se ubica el Barrio Residencial Sierra de Los Padres, un asentamiento de casas de descanso y fin de semana en constante crecimiento dónde residen más de mil familias en forma permanente.

En tal contexto, el humedal brinda beneficios que mejoran la calidad de vida tanto de la población local como de los turistas ofreciendo el disfrute de SE (como abastecimiento de agua subterránea a distintos usos, producción de materias primas biológicas, regulación hídrica y depuración de aguas; y otros servicios culturales como los recreativos, educativos, paisajísticos y estéticos).

Se espera dar a conocer los SE presentes en la Laguna, ponderar su valor económico como insumo potencial en la toma de decisiones y el diseño de planes de manejo del ecosistema, así como su contribución metodológica a la valoración de ecosistemas similares. 
Figura 3. Imagen satelital de la laguna

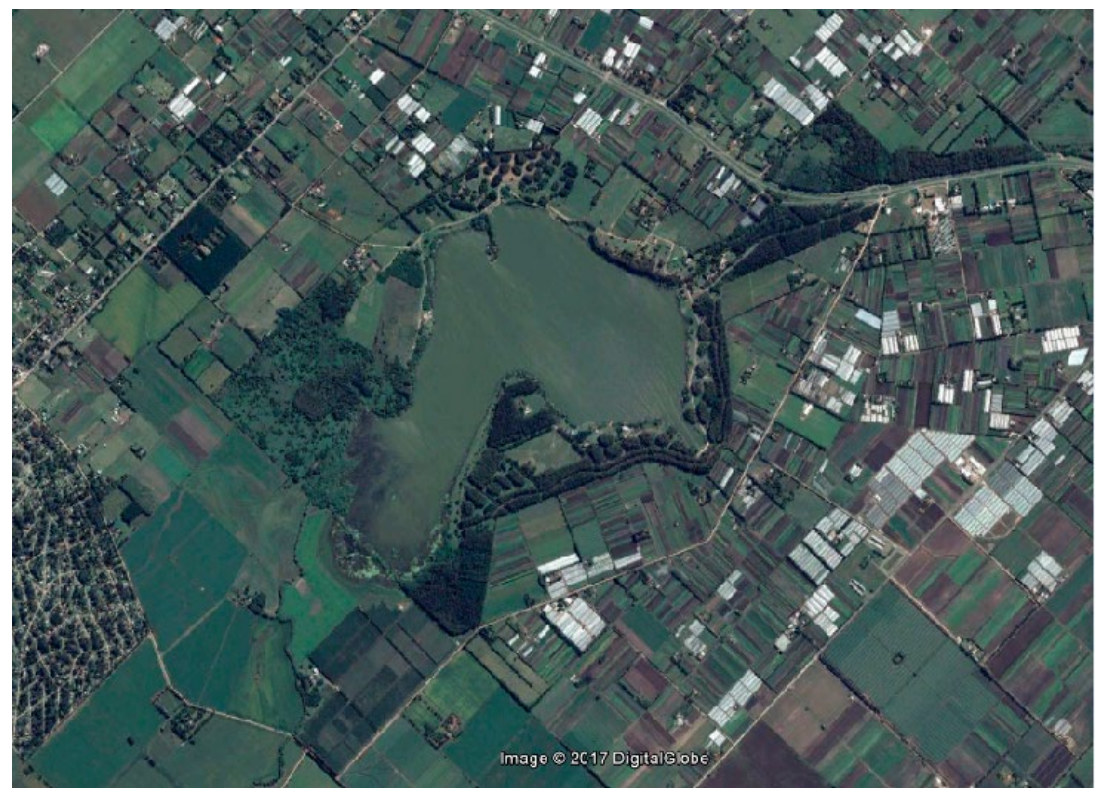

Fuente: Google Earth, diciembre 2015.

\section{Metodología}

Para la etapa del diagnóstico se han aplicado técnicas de observación directa simple y observación documental. La modelización ecosistémica resultó útil para establecer cuáles son y cómo interactúan los distintos componentes del sistema y sus funciones, en forma simplificada (Marten, 2001).

La aproximación a VET de los SE de la laguna comprendió cuatro etapas o fases:

1) Identificación de los servicios ecosistémicos presentes en la laguna

2) Selección de los SE a valorar en función de su importancia, la disponibilidad de información y técnicas para su valoración física y económica.

3) Valoración en unidades físicas no crematísticas y su posterior valoración económica de los SE seleccionados. Para el cálculo del servicio de abastecimiento de agua se realizó el balance hídrico utilizando el método de Thornthwaite y Matter (1957), y para su valoración económica se tuvieron en cuenta los costos de producción de agua. Para el Control de erosión se utilizó la Ecuación Universal de la Pérdida de Suelo (USLE) (Wischmeyer y Smith, 1978).

USLE es un método que utiliza seis factores: erosividad de la lluvia (R), susceptibilidad de erosión del suelo (K), largo de la pendiente (L), magnitud de la pendiente (S), cubierta y manejo de cultivos (C), y prácticas de conservación (P), para estimar la pérdida de suelos promedio (A) por el período de tiempo representado por $\mathrm{R}$, generalmente un año (FAO, 1993). La ecuación que representa la pérdida de suelo por unidad de superficie ( $\mathrm{t} / \mathrm{ha} / \mathrm{año}$ ) es: A = R.K.L.S.C.P; donde R: factor erosividad de la lluvia ( $\mathrm{mm} / \mathrm{ha})$; $\mathrm{K}$ : factor de erodabilidad del suelo (t. ha/ha.mm); LS: longitud y grado de la pendiente; C: factor de cobertura del suelo y P: factor de práctica, de manejo de cultivos

Para calcular R se tuvo en cuenta el Método de Young (Pando Moreno, Gutiérrez Gutiérrez, Maldonado Hernández, Palacio Prieto y Estrada Castillón, 2003) en el cual: R= 0.5 x Precipitación, como las PP promedio son de 911 , resultó ser 455,4.

Para calcular K la ecuación empleada es: K= FT (12 - MO) + FE + FP. Donde FT: factor textura; MO: Porcentaje de Materia Orgánica; FE: Factor estructura; FP: Factor permeabilidad.

En base al Mapa de Suelos de la Provincia de Buenos Aires (1989)7 (Secretaría de Agricultura, Ganadería y Pesca. Instituto Nacional de Tecnología Agropecuaria [INTA], 1989) el suelo de la Cuenca de

7 Escala 1: 500.000 . 
la Laguna de los Padres es Argiudol Típico, franco fino $\left(\mathrm{M}_{17} \mathrm{tc}^{3}\right)$ y se caracteriza por poseer una textura franco-arcillosa y estar muy provisto de materia orgánica (6\%).

FT, FE y FP se encuentran tabulados según las principales clases texturales de suelo en el Manual del Modelo GLEAMS (Knisel, Leonard, Davis \& Sheridan, 1991). Los datos Son: 35 \% arcilla, 30 \% limo, 35 \% arena, FT, 0,0236; FE 0,065, FP 0,05, MO, 6 y K 0,2566

Para calcular LS la ecuación es (USDA Agriculture Handbook, 1978): LS= $(\mathrm{L} / 22,13)^{\mathrm{m}} \cdot(0,065+$ $\left.0,045 . S+0,0065 . S^{2}\right)$, donde L: longitud de la pendiente o ladera $(\mathrm{m})$; S: pendiente (\%), m: constante. $\mathrm{m}$ $=0,5$ si $\mathrm{S}<5 \% ;=0,4$ si $3,5<\mathrm{S}<4,5 ;=0,3$ si $1<\% \mathrm{~S}<3 ;=0,2$ si $\% \mathrm{~S}<1$.

Considerando los datos obtenidos para la zona por el Instituto de Geología de Costas se obtiene:

\begin{tabular}{|c|c|c|c|}
\hline L & S & m & LS \\
\hline 500 & 3 & 0,3 & 0,659 \\
\hline
\end{tabular}

Para calcular $C$ hay valores medios preestablecidos según el tipo de cubierta. Teniendo en cuenta la tabla generada por Delgado y Vásquez (1997); revisado por Cortolima $(2006)^{8}$ se ha calculado un promedio entre los siguientes tipos de cobertura (Tabla 1):

Tabla 1. Factor de cobertura del suelo

\begin{tabular}{|c|c|}
\hline Cultivo & Factor C \\
\hline Maíz (alta densidad) & 0,415 \\
\hline Trigo(alta densidad) & 0,580 \\
\hline Zanahoria & 0,690 \\
\hline Papa & 0,610 \\
\hline Soja (alta densidad) & 0,415 \\
\hline Promedio & $\mathbf{0 , 5 4 2}$ \\
\hline
\end{tabular}

Fuente: Delgado y Vásquez, 1997.

P es el factor utilizado para diferentes prácticas y obras de conservación del suelo y agua y al igual que para el factor $C$ hay valores medios ya calculados. En la zona bajo estudio hay curvas de nivel en las laderas y escurrimiento por surcos del riego por aspersión. Acorde a la tabla propuesta por el Instituto para la Conservación de la Naturaleza [ICONA] (1988) y Rodríguez, Florentino, Gallardo y García (2004):

\begin{tabular}{|cc|}
\hline Práctica utilizada & Factor P \\
\hline Surcado al contorno & 0,75 \\
\hline
\end{tabular}

A partir de estos valores se obtiene que $A=31,31$ t/ha/año

La identificación y localización de los distintos usos del suelo se basó en CORINE LandCover [CLC 2000], trabajando hasta el nivel 3. Mediante la interpretación de imágenes Landsat y del Google Earth Pro y el reconocimiento de campo se completó el relevamiento de los distintos tipos de coberturas del suelo en el área que luego se digitalizaron en pantalla mediante el software SIG ArcGis 9.2. y para su valoración económica se realizó en base al criterio propuesto por Agudelo Patino y Correa Restrepo (2000). Para la evaluación del secuestro potencial de carbono se ha realizado la estimación de la biomasa acumulada de los diferentes componentes vegetales (Guerrero y Culós, 2007; FAO 2002; Serrada, Montero y Reque, 2008; Cordova Reyes, 2008). Y el cálculo del SE valor de existencia de la biodiversidad -un valor de no uso que considera el valor intrínseco del recurso biológico- se determinó a partir de considerar el monto que la sociedad está dispuesta a pagar -disponibilidad a pagar- para conservar ese bien a futuro cuanto destina el estado en conservación de áreas destinadas a su conservación (Azqueta y Field, 1998; Izko y Burneo, 2003; Lomas et al., 2005; Guerrero, Sosa, Rodríguez y del Fresno, 2013).

8 Tabla 2.144 "Valores de C para diferentes cultivos" 
4) Finalmente, se obtiene una aproximación al VET de la laguna y su comparación con el presupuesto Municipal. La Figura 4 sintetiza los posibles valores del VET para un ecosistema o bien natural. Algunos de los SE son posibles de ser valorados crematísticamente a partir de esta conceptualización. Una forma de dimensionar el peso económico local del VET obtenido para los SE es compararlo con otros bienes socialmente sensibles como el porcentaje del presupuesto local destinado por ejemplo a la salud o la educación.

Figura 4. Valor económico total y métodos de valoración económica

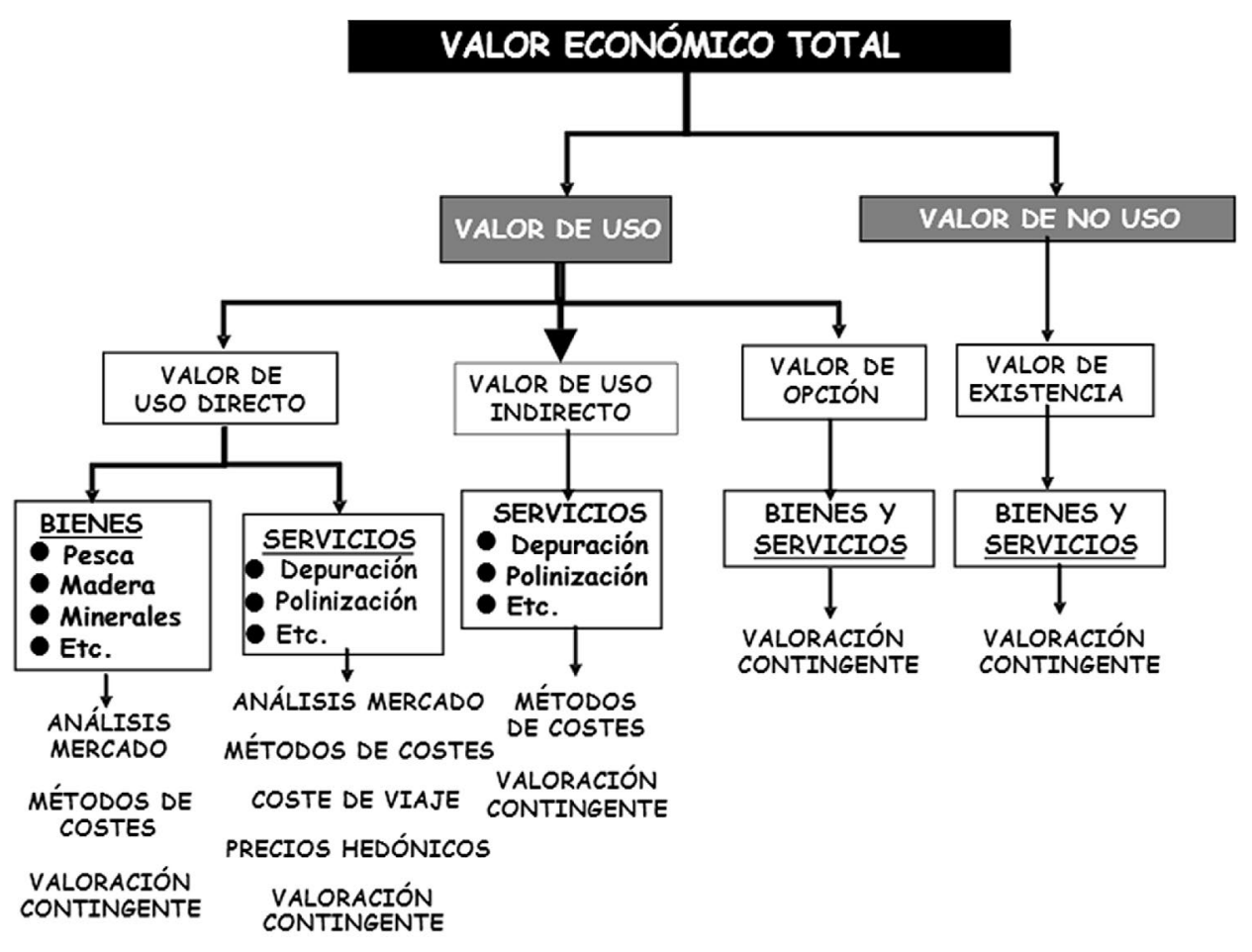

Fuente: Barbier et al., 1997.

\section{Resultados}

De los SE presentes en la laguna se seleccionaron 4 en función de la disponibilidades de información y metodologías disponibles para su valoración en unidades físicas y crematísticas. Esos SE son: abastecimiento de agua, control de la erosión, capacidad de secuestro $\mathrm{CO}_{2}$, y valor de existencia

Para el cálculo del servicio se tuvieron en cuenta datos hidrológicos provistos por el Grupo de Investigación de Hidrogeología perteneciente al Instituto de Geología de Costas y del Cuaternario de la Facultad de Ciencias Exactas de la Universidad de Mar del Plata. El balance hídrico se realizó de acuerdo al método de Thorntwaite y Matter (1957). El servicio se ponderó considerando como indicador la recarga del acuífero.

\subsection{Valoración económica del servicio de abastecimiento de agua}

Se emplearon los datos de precipitaciones correspondientes a la Estación La Peregrina para toda la Cuenca (LLP) (1985- 2008), expresados en mm/año: pp. Total: 911,24; ETP 736,52; escorrentía: 36,45 y recarga: 138,27. Considerando que la superficie de la cuenca es de $102,6 \mathrm{~km}^{2}$ y que la recarga media del sistema subterráneo es 138,27 mm/año se obtuvo que la recarga de la cuenca es de $14,16 \mathrm{hm}^{3} / \mathbf{a n ̃ o}$.

Los datos económicos empleados para el cálculo (tabla 1) se extrajeron del Informe Anual 2012 del Grupo Regional de Trabajo de Benchmarking [GRTB] perteneciente a la Asociación de Entes Reguladores de Agua Potable y Saneamiento de las Américas [ADERASA].

A partir del valor del $\mathrm{m}^{3}$ de cuenta y la recarga anual de la cuenca, se obtuvo el valor monetario del servicio ambiental de la recarga media anual para la Cuenca Laguna de los Padres cercana a los 4 millones de pesos (tabla 2). 
Tabla 2. valores económicos

\begin{tabular}{|lr|}
\hline Producción de agua (m³/día. cuenta) & 1,13 \\
Producción de agua (m³/año. cuenta) & 412,45 \\
\hline Costos totales (USD/cuenta) & 115,06 \\
Costos totales (USD/m³) & 0,28 \\
\hline
\end{tabular}

Fuente: GRTB, 2012.

Tabla 3. Valor del servicio para la recarga anual de la Cuenca Laguna de los Padres (USD)

\begin{tabular}{|c|c|c|}
\hline Valor del servicio $\left(\mathrm{USD} / \mathrm{m}^{3}\right)$ & Volumen de recarga ( $\left.\mathrm{m}^{3} / a n ̃ o\right)$ & $\begin{array}{l}\text { Valor del servicio para la recarga anual } \\
\text { de la Cuenca Laguna de los Padres (USD) }\end{array}$ \\
\hline 0,28 & 14.158 .800 & 3.964 .464 \\
\hline
\end{tabular}

Fuente: Guerrero et al., 2013. Elaboración propia.

\subsection{Valoración económica del servicio de control de erosión}

El clima, el suelo, la topografía, y las prácticas de conservación y manejo de cultivos, afectan la erosión del suelo $(\mathrm{FAO}, 1993)^{9}$. La remoción de la capa superficial del suelo debido a la erosión provoca efectos en las características físicas y químicas del mismo, produciendo reducción en la infiltración del agua y disminución en su capacidad de almacenaje (Castillo y Müller-Sämann, 1996).

Los suelos pampeanos presentan excelentes condiciones para la práctica de la agricultura, aunque también explica la degradación paulatina que van sufriendo por excesiva actividad y por el avance de la frontera agrícola. De encontrarse erosionados, producto de prácticas no planificadas, peligran sus funciones ecosistémicas, entre ellas su capacidad de retención de nutrientes como también los servicios ambientales que brindan.

Para determinarla erosión se empleó la Ecuación Universal de la Pérdida de Suelo (USLE) propuesta por Wischmeyer y Smith en 1978 (Conill y De Pablo, 2007; Cerdà, 2001; Pando Moreno et al. 2003; Rodríguez et al. 2004) mediante el cual se calcula las tasas de erosión de espacios geográficos uniformes a partir de los factores más relevantes (Conill y De Pablo, 2007).

Teniendo en cuenta que la superficie de la zona de estudio es 10.260 ha y la erosión promedio se produce a una tasa de $31,31 \mathrm{t} / \mathrm{ha} / \mathrm{año}$ se estima una pérdida de suelo igual $\mathrm{a}^{10}: 321.240,6 \mathrm{t} / \mathrm{año}$

Para el cálculo monetario se utilizó el valor obtenido por Agudelo Patino y Correa Restrepo (2000) ${ }^{11}$ para el servicio control de la erosión en bosques y praderas. Los valores generados para los servicios ambientales de distintos ecosistemas se exponen en la tabla 4.

Tabla 4. Valor económico de los servicios ambientales por ha y tipo d ecosistema, en USD

\begin{tabular}{|c|c|c|c|c|}
\hline Producción alimentos & 67,83 & & & \\
\hline Regulación agua & & 6838,20 & 2,52 & 3,77 \\
\hline $\begin{array}{c}\text { Formación suelos } \\
\text { Regulación gases }\end{array}$ & & & \\
\hline $\begin{array}{c}\text { Abastecimiento agua } \\
\text { Control erosión } \\
\begin{array}{c}\text { Aportes bellezas escé- } \\
\text { nicas y paisajística }\end{array}\end{array}$ & 2770,37 & & 8,79 \\
\hline
\end{tabular}

Fuente: Agudelo Patino y Correa Restrepo (2000).

9 Erosión de suelos en América Latina

10 Total $=10.260$ ha/año $\times 31,31$ t/ha/año.

11 La Controlaría General de Antioquia, en Colombia calculó el valor de los servicios ambientales por hectárea y tipo de ecosistema y la valoración económica de los beneficios obtenidos por el cumplimiento del artículo 111 de la ley 99 de 1993 . Informe sobre el estado de los recursos naturales y del ambiente en Antioquia 2003-2004 en: http://www.contraloriagdeant.gov.co/docs/mambiente/2004/cap3 $\underline{\text { libro.htm }}$ 
Se reconoce no obstante, la debilidad metodológica del uso de datos provenientes de la literatura de referencia disponible, no obstante se destaca como objetivo de brindar una aproximación al valor del servicio que no está incluido en los precio de mercado cuando se comercializa el recurso (suelo) ya que el precio solo incluye los costos de extracción, cuanto me cuesta sacar suelo o evitar la erosión del suelo.

Sabiendo que la pérdida de suelo es equivalente a 321.240,6 t/año se calculó el valor monetario del servicio total de control de la erosión (VCE) para el período de un año:

$$
\mathrm{VCE}=321.240,6 \text { t/año } \times 36,45 \mathrm{USD} / \mathrm{t}=11.709 .219,87 \mathrm{USD}
$$

\subsection{Valoración económica del Servicio de Secuestro de Carbono}

Se trata de un servicio de regulación del clima a través de la absorción de gases de efecto invernadero. Para la evaluación del SE se determinó el secuestro potencial de Carbono a partir de la estimación de la biomasa acumulada de los diferentes componentes vegetales del ecosistema bajo estudio (Guerrero y Culós, 2007). Se emplean los datos de superficies y clases de vegetación del mapa de cobertura de usos del suelo de la cuenca realizado por Romanelli et al., (2012).

La figura 5 y la tabla 5 muestran y clasifican respectivamente los usos del suelo en la Cuenca Laguna de los Padres mediante esta metodología.

Figura 5. Cobertura del suelo Cuenca Laguna de los Padres

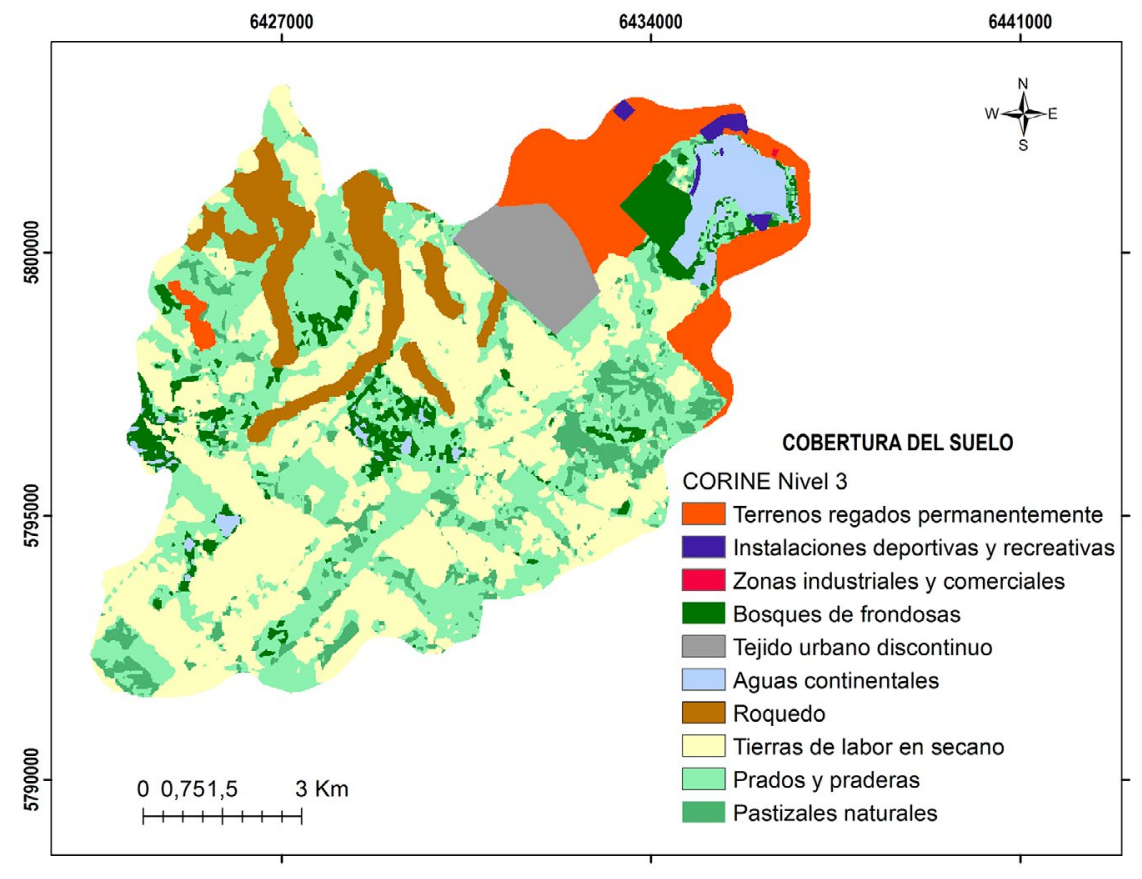

Fuente: Romanelli et al., 2012

A la superficie correspondiente a los distintos tipos de cobertura del suelo y se les asignó un índice de secuestro promedio en base a información antecedente sobre capacidad de secuestro de carbono media por especie (fijación media anual en tabla 6).

Una vez calculada la capacidad biofísica de secuestro se determinó el valor económico del SE considerando tres escenarios posibles de precios ${ }^{12}$ frente a la ausencia de un precio único: E1: US\$20/t CO, E2: US\$10/t $\mathrm{CO}_{2}$ y E3: US\$3/t CO (Guerrero et al. 2013).

\footnotetext{
12 Una forma de determinar valores del SE puede ser considerar la literatura de referencia. En la valoración de bosques en México se emplearon los valores propuestos por Fankhauser (2013) de 20 USD/t C. Otras estimaciones de proyectos forestales en el trópico oscilan entre los 2 y 25 USD/t C, y entre los 5 y 15 USD. Estas no incluyen los costos de oportunidad de la tierra, la infraestructura, monitoreo y recopilación de datos asociados a los proyectos. Kauppi \& Sedjo (2001) estimaron para actividades forestales y de uso de la tierra en países industrializados en 7,5 USD/tC. Missfeldt y Haites (2001) obtuvieron un valor de 15USD/ton C. Van der Linden Solomonidis, Spence, Li, y Paul (1999) analizó 280 proyectos de energía potenciales en países en vías de desarrollo y concluyó que el equivalente de $200 \mathrm{MtC}$ se podría reducir por año a un costo de 10USD/ton C. Otra opción es considerar los precios en los mercado de carbono -Chicago o Ámsterdam- que varían entre los 5 y 10 USD/ton C, valores algo menores que los de la literatura de referencia (Guerrero y Culós, 2007).
} 
Tabla 5. Tipología de terrenos

\begin{tabular}{|c|c|c|}
\hline CLASES & TIPOLOGÍA DE LOS TERRENOS & CARACTERÍSTICAS \\
\hline Clase 2.1.2. & Regados Permanentemente & $\begin{array}{l}\text { Cultivos regados permanentemente o periódicamente, utilizando una infraestructura } \\
\text { permanente (canales de riego, redes de drenaje). Incluye toda la zona hortícola de } \\
\text { Laguna de Los Padres. }\end{array}$ \\
\hline Clase 2,2.1 & Tierras de labor en secano & $\begin{array}{l}\text { Cultivos de soja, maíz, trigo y girasol. Su crecimiento requiere aplicación de } \\
\text { fertilizantes y pesticidas. Métodos agrícolas modernizados e intensificados en el } \\
\text { tiempo hacia la producción comercial }\end{array}$ \\
\hline Clase 2.3.1. & Prados y Praderas & $\begin{array}{l}\text { Cobertura herbácea densa, de composición floral, dominada por gramíneas, no bajo } \\
\text { un sistema de rotación. Utilizados principalmente para pasto pero pudiendo haber } \\
\text { recogida mecánica para forraje. }\end{array}$ \\
\hline Clase 3.1.1. & Bosques de Frondosas & $\begin{array}{l}\text { Formaciones vegetales compuestas principalmente por árboles, incluyendo monte } \\
\text { bajo de arbustos, donde predominan las especies de frondosas. Esta clase incluye } \\
\text { zonas con una cubierta vegetal mayor del } 30 \% \text {. Se asignaron a esta clase los montes } \\
\text { de pino y eucaliptos, como también la Reserva del Curral de Laguna de Los Padres. }\end{array}$ \\
\hline Clase 3.2.1. & Pastizales Naturales & $\begin{array}{l}\text { Los pastizales naturales son zonas con vegetación herbácea (la altura máxima es } \\
150 \mathrm{~cm} \text { y prevalecen las especies de gramíneas) que cubre al menos el } 75 \% \text { de la } \\
\text { superficie cubierta por vegetación que se desarrolla bajo una interferencia humana } \\
\text { mínima (no se riega, fertiliza o estimula con productos químicos que puedan } \\
\text { influir en la producción de biomasa). Se incluyeron en esta clase las áreas-relicto de } \\
\text { pastizal pampeano (conformado principalmente por espartillar, junco, cortaderal y } \\
\text { vegetación psamófita, en orden de superficie ocupada). }\end{array}$ \\
\hline
\end{tabular}

Fuente: Romanelli et al., 2012.

En el caso de la valoración del SE secuestro de carbono se emplean diferentes escenarios de precios porque aunque para este servicio existen mercados (Chicago, La Haya, Tokio) que fijan precio de la tonelada de Carbono, están subvalorados, y en este caso corresponden al escenario E2. No obstante, los precios asignados a los escenarios El y E3 fueron obtenidos en una variedad de ecosistemas a través de métodos como la disponibilidad a pagar (Método de costo de viaje o Valoración contingente, por ejemplo) y muestran diferencias considerables en la valoración del servicio. El empleo de escenarios tiene como intención exponer tales diferencias.

Tabla 6. Superficies de fijación/secuestro Carbono y valor económico total del servicio

\begin{tabular}{|c|c|c|c|c|c|c|c|}
\hline \multirow{2}{*}{ Áreas } & Sup. & Sup. cubierta & $\begin{array}{c}\text { Fijación media } \\
\text { anual spp. }\end{array}$ & $\begin{array}{c}\text { Valor } \\
\text { fijación }\end{array}$ & \multicolumn{2}{|c|}{ Valor económico (USD) } \\
\cline { 2 - 7 } & (ha) & $\%$ & (tC/ha/año) & (tC) & 20 & 10 \\
\hline Tierras de labor en secano & 3.693 & 36 & $3,6^{13}$ & $13.294,8$ & 265.896 & 132.948 & $39.884,4$ \\
\hline Prados y praderas & 2.811 & 27,4 & $3^{14}$ & 8.433 & 168.660 & 84.330 & 25.299 \\
\hline $\begin{array}{c}\text { Terrenos regados } \\
\text { permanentemente }\end{array}$ & 981 & 9,56 & $7,8^{15}$ & $7.651,8$ & 153.036 & 76.518 & $22.955,4$ \\
\hline $\begin{array}{c}\text { Pastizales naturales } \\
\text { Bosques de frondosas }\end{array}$ & 635 & 6,19 & $0,2^{16}$ & 127 & 2.540 & 1.270 & 381 \\
\hline Total & 8.690 & 84,71 & $30^{17}$ & 17.100 & 342.000 & 171.000 & 51.300 \\
\hline
\end{tabular}

Fuente: Guerrero et al., 2013, Romanelli et al., 2012. Elaboración propia.

El valor total del Índice Secuestro de Carbono para la cuenca de la Laguna de los Padres resultó ser de: 466.066 USD o 3.975.542,98 \$ equivalentes a la cotización dólar noviembre 2015.

\subsection{Valoración económica de Biodiversidad}

Los valores de existencia hacen referencia al valor que los humanos asignan a los ecosistemas y en particular a la diversidad biológica por su mera existencia y la posibilidad de mantenerlas para las ge-

13 Promedio de la fijación media anual de la avena (3,8 tC/ha/año), cebada (3,2 tC/ha/año) y trigo (3,8 tC/ha/año). Victoria Jumilla, 2010. 14 FAO, 2002.

15 Promedio de la fijación media anual del tomate (8,7 tC/ha/año) y la lechuga (6,9 tC/ha/año). Victoria Jumilla, 2010.

16 Cordova Reyes, 2008.

17 Promedio fijación media anual pinares (19 tC/ha/año) y otros eucaliptus (40 tC/ha/año) (Guerrero et al., 2013; Serrada, et al., 2008; Cordova Reyes, 2008; Kandus et al., 2009; Guerrero y Culós, 2007; García Huber y Guerrero, 2006; García Iturrath, 2008). 
neraciones futuras. Comprende la conservación de hábitats, especies, genes y ecosistemas. Saber que la selva tropical húmeda, la ballena azul o el panda continúan existiendo proporciona satisfacción a la gente, aunque nunca lleguen a ver a uno de estos ejemplares de cerca. El valor de existencia está ligado estrechamente a valores culturales y hasta religiosos. La percepción de estos valores se establece de forma social y a menudo aumenta conforme aumenta el ingreso (Keppler, 1999). Una medida indirecta y subjetiva del valor de la biodiversidad es la disposición a pagar o aceptar que refleja las preferencias individuales por un bien o servicio ambiental, siendo la valoración económica de un recurso natural o ambiental la medida monetaria de las preferencias de los individuos. La valoración económica permite determinar una curva de demanda para los bienes y servicios ambientales; es decir, el valor que las personas le asignan a los recursos biológicos, expresado en términos monetarios (Azqueta y Field, 1998).

Para el cálculo del valor de existencia de la biodiversidad de la laguna se tomó en cuenta el Índice de Conservación generado por Guerrero et al., 2013. El mismo se obtuvo a partir de aplicar métodos de costos alternativos, los cuales asignan en forma indirecta valores objetivos de bienes sustitutos próximos.

Guerrero et al. (Op. Cit.) consideran que una medida de la "disponibilidad a pagar por conservación de áreas naturales" es estimar el valor/ha/año asociado a administrar estos espacios. En el caso argentino la Administración de Parques Nacionales [APN] es el organismo encargado de gestionar la conservación a nivel nacional. Una forma de determinar el costo de oportunidad de conservar/preservar áreas naturales y su biodiversidad (su existencia) es posible al considerar: a) el monto (\$/año 2013) del presupuesto nacional destinado a la inversión directa más asignación por entidad que le corresponde a esta administración ${ }^{18}$ y b) la superficie total de áreas de conservación que administra la $\mathrm{APN}^{19}$. A partir de allí se estableció un valor de conservación anual por hectárea de $\$ 47$.

Para determinar el valor de existencia de la laguna se extrapoló ese valor a dos escenarios: 1. La superficie de la Reserva Laguna de los Padres y 2. La superficie de la cuenca Laguna de los Padres como puede verse en la tabla 7. Mientras que la tabla 8 resume el VET asociado al humedal Laguna de los Padres.

Tabla 7. Valor de conservación/existencia

\begin{tabular}{|ccc|}
\hline Área & Superficie (ha) & Valor existencia (\$) \\
\hline Reserva Laguna de los Padres & 216 & 10.152 \\
\hline Cuenca Laguna de los Padres & 10.260 & 482.220 \\
\hline
\end{tabular}

Fuente: Guerrero et al, 2013. Elaboración propia.

Tabla 8. Valor Económico Total del Humedal Laguna de los Padres

\begin{tabular}{|c|c|c|c|c|}
\hline \multicolumn{3}{|c|}{ VALOR DE USO } & \multicolumn{2}{|c|}{ VALOR DE NO USO } \\
\hline Uso Directo & Uso indirecto & Valor de opción & Valor de Legado & Valor de Existencia \\
\hline $\begin{array}{l}\text { Productos directamente } \\
\text { consumibles. }\end{array}$ & $\begin{array}{l}\text { Beneficios derivados de } \\
\text { funciones eco sistémicas }\end{array}$ & $\begin{array}{c}\text { Valores futuros directos } \\
\text { e indirectos }\end{array}$ & $\begin{array}{c}\text { Valor más intangible. } \\
\text { Cuestiones éticas y } \\
\text { estéticas. }\end{array}$ & $\begin{array}{l}\text { Valor intrínseco que tiene } \\
\text { cada recurso por existir }\end{array}$ \\
\hline $\begin{array}{l}\text { Alimento, biomasa, } \\
\text { recreación, turismo, } \\
\text { educación, salud, etc. }\end{array}$ & $\begin{array}{l}\text { Regulación hídrica, } \\
\text { depuración y } \\
\text { abastecimiento de agua, } \\
\text { control de la erosión, } \\
\text { secuestro de carbono, etc. }\end{array}$ & $\begin{array}{l}\text { Bio-prospección, } \\
\text { conservación de hábitats } \\
\text { para posibles usos } \\
\text { futuros. }\end{array}$ & $\begin{array}{c}\text { Biodiversidad, cultura, } \\
\text { patrimonio. }\end{array}$ & $\begin{array}{l}\text { Hábitat, especies, genes, } \\
\text { ecosistemas, etc. }\end{array}$ \\
\hline
\end{tabular}

Fuente: Pearce y Moran, 1994. Elaboración propia.

La tabla 9 expresa los valores económicos de los servicios ambientales seleccionados y los compara con el presupuesto anual del Partido de General Pueyrredón para el 2014. Como resultado el VET es equivalente al 4,6\% del presupuesto total anual del Municipio.

18 El presupuesto para Parques Nacionales en el 2013 fue de \$174.295.000 (Ministerio de Economía de la Nación).

19 La superficie total de Parques Nacionales y Monumentos Históricos que gestionaba la APN en el 2013 era de 3.687 .510 has. (Instituto Geográfico Nacional [IGN], 2013). 
Tabla 9.Valoración Económica Total de los SE de la Cuenca Laguna de los Padres (\$/año)

\begin{tabular}{|c|c|c|}
\hline Servicios Ambientales & $\begin{array}{l}\text { Valor monetario } \\
\text { servicio }(\$)^{20}\end{array}$ & $\begin{array}{c}\text { Presupuesto Partido } \\
\text { de General Pueyrredón } \\
2014 \text { (\$) }\end{array}$ \\
\hline Secuestro de carbono & $3.975 .542,98$ & \multirow{5}{*}{$2.994 .221 .600,92^{21}$} \\
\hline Recarga del acuífero & $33.816 .877,92$ & \\
\hline Control de la erosión & $99.879 .646,6$ & \\
\hline Valor de existencia & 482.220 & \\
\hline Valor económico total & $138.154 .287,5$ & \\
\hline
\end{tabular}

Fuente: Guerrero et al., 2013. Elaboración propia.

\section{Discusión}

Es necesario señalar que en la literatura sobre el tema se evidencian diferencias claras en el entendimiento y uso del concepto de SE (Hermlingmeier y Nicholas, 2017).

En ese sentido, por ejemplo es controvertida la inclusión de la biodiversidad como un SE. En particular, en el enfoque ecosistémico se enfatiza que las diferencias entre biodiversidad y SE tienen que ser consideradas en un contexto social y económico más amplio. Y se sugiere que los ecologistas busquen formas para relacionar sus investigaciones sobre cómo funcionan los ecosistemas enfatizando un entendimiento más amplio de cómo la gente se beneficia de los servicios de la naturaleza, y cómo se puede ayudar a sostener y mejorar su bienestar. En ese contexto es posible que muchos de los conceptos básicos necesiten ser repensados, incluida la noción de ecosistema (Haines-Young, \& Potschin, 2010.

No obstante el desafío más grande parece estar vinculado a la valoración de los beneficios de los SE y a las herramientas metodológicas tendientes a asignar valor a esos SE.

Desde un enfoque de mercado -aunque no el único sistema de valor posible- asignar valores crematísticos a la naturaleza permite expresar en un lenguaje políticamente comprensible un reclamo ambiental que puesto en otras unidades de valor posiblemente no sea considerado y/o interpretado (Guerrero et al., 2013).

Las técnicas de valoración económica no apuntan a ofrecer un valor de la biodiversidad per se, sino a estimar el valor económico asociado a ciertos bienes o servicios compatibles con la conservación de la misma (Figueroa, 2005).

En ese contexto la valoración monetaria puede considerarse como un dato añadido, pero no expresa la totalidad de valores ecológicos, sociales y culturales que se deberían tener en cuenta en el proceso de toma de decisiones (De Groot, Wilson y Boumans, 2002).

Se plantea como desafío futuro la inclusión de los servicios ecosistémicos como herramientas de planificación integrada y de toma decisiones. No obstante, quedan por resolver muchas complicaciones metodológicas en la valoración crematística de los SE.

Algunos autores (De Groot et al., 2010; Daniel et al., 2012) discuten las posibilidades de integración entre valores económicos y otro tipo de valores como los culturales, estéticos y espirituales presentes en un ecosistema. Dicha posibilidad supone analizar diferentes epistemologías y metodologías científicas provenientes tanto de disciplinas ecológicas como sociales que colaboren en la valoración total de los SE.

En coincidencia, Daniel et al., (2012) dice que la literatura ofrece ejemplos de cómo avanzar en la integración de un rango amplio de ciencias sociales podría ampliar la perspectiva de la valoración de bienes y servicios ambientales públicos compartidos y colaborar en el diseño de políticas y toma de decisión.

\footnotetext{
20 Los índices cuyo valor había sido calculado en dólares (USD) se convirtieron a pesos tomando el valor del precio oficial del dólar para la venta al día 05 de noviembre del 2014 a 8,53. http://www.lanacion.com.ar/dolar-hoy-t1369

21 http://www.cazadordenoticias.com.ar/secciones/economia/16/11/2013/nota/00052041/
} 


\section{Conclusiones}

El conocimiento de la situación ambiental de los beneficios ecosistémicos del humedal Laguna de los Padres permitió expresar en términos económicos una medida aproximada -posiblemente infravaloradadel VET de los SE que asciende a más de 138 millones de pesos/año, equivalentes al 4,6\% del presupuesto total anual del Municipio para el año 2014. Es interesante comparar este valor con otras inversiones sociales del presupuesto municipal de casi 300 millones de pesos. Por ejemplo, en educación la inversión anual alcanza el 28\%, o en salud un $21.23 \%$. Y para obras públicas se destinan 400 millones de pesos -un 13 \%- mientras que a la nueva Secretaría de Seguridad y Control recibió más de 183 Millones -un 6 \%-.

Frente a estos valores cabe preguntar cuál es el rol que cumple el ambiente en la planificación del gobierno local como inversión pública. Aunque es mas importante lo que implica presupuestariamente hablando no incluir en la toma de decisiones "bienes ambientales" que se equiparan al 4,6\% del presupuesto municipal

Para que los lenguajes crematísticos de valoración dejen de prevalecer y se discutan otros valores presentes en la valoración de servicios ecosistémicos y culturales, es fundamental fortalecer las actividades de comunicación y difusión, la creación de conciencia ambiental y el empoderamiento social en la toma de decisiones sobre el ambiente y sus funciones. De esto se pueden derivar cuestiones muy importantes como: la participación ciudadana y los medios de comunicación.

\section{Referencias}

Agudelo Patino, L. Correa Restrepo, F. (2000). Directrices para la Gestión Ambiental Urbano-Rural. Medellín: Universidad Nacional- Corantioquia.

Aguilera, H. y Murillo, J. M. (2009). The effect of possible climate change on natural groundwater recharge based on a simple model: a study of four karstic aquifers in SE Spain. Environmental Geology (57), 963-974. https://doi.org/10.1007/s00254-008-1381-2

Asociación de Entes Reguladores de Agua Potable y Saneamiento de las Américas [ADERESA]. 2012. Informe Anual del (2012). Grupo Regional de Trabajo de Benchmarking [GRTB] http://www.eras.gov. ar/pdf/2012 Informe Anual GRTB-ADERASA.pdf

Azqueta D. y Field, B. (1998). Economía y Medio Ambiente. Bogotá, Colombia: McGraw Hill.

Baccaro, K., Degorgue, M., Lucca, M., Picone, L., Zamuner, E., \& Andreoli, Y. (2006). Calidad del agua para consumo humano y riego en muestras del cinturón hortícola de Mar del Plata. RIA. Revista de Investigaciones Agropecuarias, 35(3), 95-110. Recuperado de http://biblioteca.org.ar/libros/210571.pdf

Barbier, E. (2011). Wetlands as naturalassets. Hydrological Sciences Journal, 56 (8), 1360-1373. http:// dx.doi.org/10.1080/02626667.2011.629787

Barbier, E., Acreman, M. \& Knowler, D. (1997). Economic Valuation of Wetlands. Cambridge: IUCN.

Bellagamaba, P. (1997). Reserva Integral Laguna de los Padres. Subsecretaría de Medio Ambiente. Municipalidad del Partido de General Pueyrredón. Informe inédito.

Bó, M., del Rio, J.L., López de Armentia, A., Cionchi, M., Osterrieth, M., Álvarez, M. y Camino, M. (2009). Aplicación de un sistema de geoindicadores para la evaluación de la calidad ambiental en agroecosistemas. Revista de geología Aplicada a la Ingeniería (23) 55-66. http://www.editoresasagai.org. ar/sites/default/files/Revista-ASAGAI-23_Mayo-2009_0.pdf

Boyd, J. y Banzhaf, S. (2007). What are ecosystem services? The need for standardized environmental accountingunits.EcologicalEconomics, 63(2),616-626.https://doi.org/10.1016/j.ecolecon.2007.01.002

Cabrera, A. L. (1976). Regiones fitogeográficas argentinas. Enciclopedia Argentina de Agricultura y Jardinería. Fascículo 1. Buenos Aires: ACME.

Castillo, F y Müller-Sämann, K. (1996). Conservación de suelos en ladera: Buscando nuevas alternativas. En Instituto Nacional de Adecuación de Tierrasl, INAT, Seminario Nacional sobre actualización en conservación de suelos en ladera (pp. 87-106). Santafé de Bogotá: INAT: CECIL.

Cerdà, A. (2001). La erosión del suelo y sus tasas en España. Ecosistemas 3 (Septiembre-Diciembre). Recuperado de http://revistaecosistemas.net/index.php/ecosistemas/article/view/268 
Cionchi, J., Schnack, E., Álvarez, J., Bocanegra, E., Bogliano, J. y Del Rio, J. (1982). Caracterización hidrogeológica y físico-ambiental preliminar de la laguna de los padres, partido g. Pueyrredón, provincia de Buenos Aires. Centro de Geología de Costas y del Cuaternario (UNMdP)-Municipalidad de General Pueyrredón.

Conill, F. y De Pablo, A. (2007). Modelización de la erosión hídrica en los suelos. Revista de Didáctica Ambiental, Año 4, N6. Recuperado de http://www.didacticaambiental.com/revista/numero6/ Sistemas3.html

Cordova Reyes, G. (2008). Captura de carbono en un pastizal de la ranchería Emiliano Zapata Centro Tabasco. Revista Divulgación México, 14(26) 49-54. Recuperado en http://revistas.ujat.mx/index.php/ kuxulkab/article/view/893

Corine Land Cover [CLC2000] (2000). European environment agency. Disponible en http://www.eea. europa.eu/data-and-maps/data/corine-land-cover-2000-clc2000-seamless-vector-database

Cortolima (2006). Informe de la Corporación autónoma regional de Tolima. Disponible en http://www. cortolima.gov.co/2006/images/stories/centro_documentos/coello/PERDIDA_SUELOS.pdf

Costanza, R. (2008). Ecosystem services: multiple classification systems are needed. Biological Conservation, 141, 350-352. https://doi.org/10.1016/j.biocon.2007.12.020

Daily, G. (1997). Nature's services: societal dependence on natural ecosystems. Washington: Island Press.

Daniel, T., Muhar, A., Arnberger, A., Aznar, O., Boyd, J. Chan, K. y Grêt-Regamey, A. (2012). Contributions of cultural services to the ecosystem services agenda. Proceedings of the National Academy of Sciences, 109(23), 8812-8819. https://doi.org/10.1073/pnas.1114773109

De Groot, R,S., Wilson, M.A., Boumans, R.M.J. (2002). A typology for the classification, description and valuation of ecosystem functions, goods and services. Ecological Economics, 41, 393-408. https://doi. org/10.1016/S0921-8009(02)00089-7

De Groot, R., Alkemade, R., Braat, L., Hein, L., y Willemen, L. (2010). Challenges in integrating the concept of ecosystem services and values in landscape planning, management and decision making. Ecological Complexity, 7(3), 260-272. https://doi.org/10.1016/j.ecocom.2009.10.006

Del Río, J. L., Massone, H., Martínez Arca, J.M., Bó, J., Bernasconi, V., Bocanegra, E., ... \& Tomás, M. (1992). Carta ambiental de la cuenca del Arroyo y Laguna de Los Padres. Informe inédito. CGCyCUNMdP-Secretaría de Desarrollo Urbano y Medio Ambiente (MGP).

Del Río, J., Caballé, M., Osterrieth, M., Kiriloskyv, Y, Bó, M., Denisienia, N. y De Marco, S. (2007). Aplicación de índices de calidad ambiental para recuperación de canteras en zonas periurbanas (Provincia de Buenos Aires, Argentina). En Actas del Congreso Internacional sobre Desarrollo, Medio Ambiente y Recursos Naturales: sostenibilidad a múltiples niveles y escalas (pp. 918-928).

Delgado, F. y Vásquez, L. (1997). Modelo Índice de Productividad aplicado a la conservación de suelos (MIPACS). Versión 2.0. Manual del usuario. Mérida, Venezuela: CIDIAT.

Esquius, K., Escalante, A. \& Solari, L. (2008). Algas epífitas indicadoras de calidad del agua en arroyos vinculados a la Laguna de Los Padres. Biología Acuática, 24, 95-102.

Fankhauser, S. (2013). Valuing climate change: the economics of the greenhouse. Abingdon, Oxfordshire: Earthscan. https://doi.org/10.1007/s10584-012-0655-6

Feria Toribio, J. y Ramos, J. (2009). Funciones ecológicas del espacio libre y planificación territorial en ámbitos metropolitanos: perspectivas teóricas y experiencias recientes en el contexto español. Scripta Nova: revista electrónica de geografía y ciencias sociales, XIII(299), 15 de septiembre de 2009. Recuperado en http://www.ub.edu/geocrit/sn/sn-299.htm

Figueroa, J. (2005). Valoración de la biodiversidad: perspectiva de la economía ambiental y la economía ecológica. Interciencia: Revista de ciencia y tecnología de América, 30(2), 103-107. Recuperado en http://search.proquest.com/openview/6c0578b952c26730bd2dbed4ef971cd5/1?pqorigsite $=$ gscholar\&cbl $=21011$

Food Agricultural Organization [FAO]. (1993). Erosión de suelos en América Latina http://www.fao.org/ docrep/t2351s/T2351S00.htm

Food Agricultural Organization [FAO]. (2002). Captura de Carbono en los Suelos para un Mejor Manejo de la Tierra. Informes Sobre recursos Mundiales de Suelos. Organización de las Naciones Unidas 
para la Agricultura y la Alimentación, Vol. 96. Recuperado de http://www.fao.org/docrep/005/Y2779S/ y2779s00.htm

Frangi, J. L. (1975). Sinopsis de las comunidades vegetales y el medio de las Sierras de Tandil (Provincia de Buenos Aires). Boletín de la Sociedad Argentina de Botánica, 16 (4), 293-319.

García Huber, S. y Guerrero, E. (2006). Indicadores de sustentabilidad ambiental en la gestión de espacios verdes. Parque urbano Monte Calvario, Tandil. Argentina. Revista de Geografía Norte Grande, 35, 45-57. https://doi.org/10.4067/S0718-34022006000100004

García Iturrath, L. (2008). Sustentabilidad ambiental parque Urbano Independencia. Tesis de licenciatura Diagnóstico y Gestión Ambiental. Buenos Aires: Facultad de Ciencias Humanas Universidad Nacional del Centro de la Provincia de Buenos Aires.

Grosman, F. (2008). Espejos en la llanura: Nuestras lagunas de la región pampeana. Buenos Aires: Editorial Universidad Nacional del Centro de la Provincia de Buenos Aires.

Guerrero, E., y Culós, G. (2007). Indicadores ambientales en la gestión de espacios verdes. El parque Cerro La Movediza. Tandil, Argentina. Revista Espacios, 28 (1), 57-73.

Guerrero, E., Sosa, B., Rodríguez, C. y del Fresno, C. (2013). Naturaleza transformada y servicios ambientales en la cuenca del Langueyú, Tandil, Argentina. Revista Estudios Ambientales, 1(1), 45-66. Recuperado de http://ojs.fch.unicen.edu.ar/index.php/estudios-ambientales/article/view/27

Haines-Young, R., \& Potschin, M. (2010). The links between biodiversity, ecosystem services and human well-being. In D. Raffaelli \& C. Frid (Eds.), Ecosystem Ecology: A New Synthesis (Ecological Reviews, pp. 110-139). https://doi.org/10.1017/CBO9780511750458.007

Hermelingmeier, V., \& Nicholas, K. (2017). Identifying five different perspectives on the ecosystem services concept using Q methodology. Ecological Economics, 136, 255-265. https://doi.org/10.1016/j. ecolecon.2017.01.006

Instituto de Estadísticas y Censos [INDEC] (2010). Censo Nacional de Personas, Viviendas y Hogares. Instituto Nacional de Estadísticas y Censos.

Instituto Geográfico Nacional [IGN] (2013). Parques Nacionales en la República Argentina. http://www. ign.gob.ar/NuestrasActividades/Geografia/DatosArgentina/ParquesNacionales

Instituto Nacional de Tecnología Agropecuaria [INTA] (1989). Mapa de Suelos de la Provincia de Buenos Aires (Escala 1: 500.000), Secretaría de Agricultura, Ganadería y Pesca.

Instituto para la Conservación de la Naturaleza [ICONA] (1988). Agresividad de la lluvia en España. Valores del factor R de la ecuación universal de pérdidas de suelo. Madrid: Servicio de publicaciones del Ministerio de Agricultura, Pesca y Alimentación - Ariel, S.A.

Iwan, A. (2015). Valoración de los servicios ambientales de la Laguna de los Padres, Argentina. Tesis de grado. Licenciatura en Diagnóstico y Gestión Ambiental. Tandil, Buenos Aires: Facultad de Ciencias Humanas, Universidad Nacional del Centro.

Izko, X. y Burneo, D. (2003). Herramientas para la valoración y manejo forestal sostenible de los bosques sudamericanos. Unión Internacional Conservación Naturaleza [UICN], Oficina Regional para América del Sur. Recuperado de http://bibliotecavirtual.minam.gob.pe/biam/handle/minam/790

Kandus, P. M., Salvia, D., Ceballos, N., Madanes, V., Capello, M., García Capello, y Morais, M. (2009). Evaluación del efecto de los incendios masivos en áreas del delta bonaerense en las islas frente a los Municipios de Baradero y Zárate. Municipio de San Pedro, Baradero y Zárate, INTA. Informe técnico en elaboración conjunta con la Estación Experimental INTA Delta y la Dirección de Recursos Naturales de la Provincia de Buenos Aires.

Kauppi, P., \& Sedjo, R. (2001). Technological and Economic Potential of Options to Enhance, Maintain, and Manage Bilogical Carbon Reservoirs and Geo-engineering. Climate Change 2001: Mitigation: Contribution of Working Group III to the Third Assessment Report of the Intergovernmental Panel on Climate Change, 3, 301.

Keppler, J. (1999). La Obtención del Valor Total de la Biodiversidad a través de la Mezcla de Instrumentos. Economía de la Biodiversidad. Memoria del Seminario Internacional de la Paz BC, 375-397.

Knisel, W., Leonard, R., Davis, F. \& Sheridan, J. (1991). Water balance components in the Georgia Coastal Plain: A GLEAMS model validation and simulation. Journal of soil and water conservation, 46(6), 450-456. 
Lomas, P. L., Martín, B., Louit, C., Montoya, D., Montes, C. \& Álvarez, S. (2005). Guía práctica para la valoración económica de los bienes y servicios ambientales de los ecosistemas. España: Fundación Interuniversitaria Fernanda González Bernáldez.

Luederitz, C., Brink, E., Gralla, F., Hermelingmeier, V., Meyer, M., Niven, L., ... \& von Wehrden, H. (2015). A review of urban ecosystem services: six key challenges for future research. Ecosystem Services, 14, 98-112. https://doi.org/10.1016/j.ecoser.2015.05.001

Marten, G. (2001). Ecología humana: conceptos básicos para el desarrollo sustentable. Earthscan Publications.

Millennium Ecosystem Assessment [MEA] (2005). Ecosystems and Human Well-Being: Synthesis (Island Press, Washington, DC).

Missfeldt, F., \& Haites, E. (2001). The potential contribution of sinks to meeting Kyoto Protocol commitments. Environmental Science \& Policy, 4(6), 269-292. https://doi.org/10.1016/S14629011(01)00039-9

Newcome, J., Provins, A., Johns, H., Ozdemiroglu, E. y Ghazoul, J. (2005). The Economic, Social and Ecological Value of Ecosystem Services: A Literature Review. London, UK: Economics for the Environment Consultancy (eftec).

Oteros Rozas, E., Martín López, B., González, J. A., y Montes, C. (2010). Un marco conceptual y metodológico integrados e interdisciplinar para la valoración de los servicios de los ecosistemas asociados a la trashumancia. In Memorias del II Congreso Nacional de Vías Pecuarias (Cáceres, 27-29 Octubre de 2010b).

Pando Moreno, M., Gutiérrez Gutiérrez, M., Maldonado Hernández, A., Palacio Prieto, J. L., y Estrada Castillón, A. E. (2003). Comparación de métodos en la estimación de erosión hídrica. Investigaciones geográficas, (51), 23-36. Recuperado en http://scielo.unam.mx/pdf/igeo/n51/n5la3.pdf

Pascual, U., Phelps, J., Garmendia, E., Brown, K., Corbera, E., Martin, A. y Muradian, R. (2014). Social equity matters in payments for ecosystem services. BioScience, 64(11), 1027-1036. https://doi. org/10.1093/biosci/biul46

Pearce, D. \& Moran, D. (1994). The economic value of biodiversity. Retrieved from https://www.google.es/ $\underline{\mathrm{url}}$ ? sa=t\&rct=j\&q=\&esrc=s\&source=web\&cd=1\&ved=0ahUKEwikqbKY2ujXAhUBwBQKHTiUCHg QFggtMAA\&url=https\%3A\%2F\%2Fwww.cbd.int $\% 2$ Ffinancial\%2Fvalues $\% 2$ Fg-economicvalue-iucn. pdf\&usg=AOvVaw3tKIYn5Ki3MoIQcbxxwip2

Pérez Bustamante, D.y Sterling, A. (2010). Elvalor económico de los bienes culturalesy ambientales. Cultura, desarrollo y sostenibilidad. Observatorio Medioambiental, 13, 41-63. Recuperado de http://search. proquest.com/openview/dcabf3766eae9a68a831ed43279a6al1/1?pq-origsite =gscholar\&cbl=54846

Pozzobon, M. y Tell, G. (1995). Estructura y dinámica de la comunidad perifítica sobre Ricciocarpusnatans (Hepaticae) de la Laguna de Los Padres (Buenos Aires, Argentina). Boletín de la Sociedad Argentina de Botánica, 30(3-4), 199-208

Rodríguez, M. F., Florentino, A., Gallardo, J., \& García, R. D. A. (2004). Sistemas de Información geográfica en la evaluación de la erosión hídrica en Badajoz-España aplicando la metodología USLE. Agronomía tropical, 54(4), 391-409. Recuperado de http://www.didacticaambiental.com/revista/numero6/ Sistemas3.html

Romanelli, A. y Massone, H.E. (2011). Interacción agua superficial-agua subterránea en lagunas del sudeste bonaerense en Lagunas de Los Padres y La Brava: un recurso natural y social para cuidar y compartir. En Massone (ed), Lagunas de Los Padres y La Brava : un recurso natural y social para cuidar y compartir (pp. 1-6). Mar del Plata: Suárez.

Romanelli, A., Lima, M. L., Londoño, O. M. Q., Martínez, D. E., y Massone, H. E. (2012). A GIS-based assessment of groundwater suitability for irrigation purposes in flat areas of the Wet Pampa Plain, Argentina. Environmental Management, 50(3), 490-503. https://doi.org/10.1007/s00267-012-9891-9

Serrada, R., Montero, G.; Reque, J. (2008). Compendio de Selvicultura Aplicada en España. INIA.

Thornthwaite, C. y Mather, J. (1957).Instructions and tables for computing potential evapotranspiration and the water balance. Centerton, NJ: Drexel Institute of Technology - Laboratory of Climatology. Climatology, Vol. X, No. 3. 311p. 
United States Department of Agriculture [USDA] Agriculture Handbook (1978). Disponible en http:// www.aet.org.es/congresos/xii/arg24.pdf

Van der Linden, M., Solomonidis, S., Spence, W., Li, N., \& Paul, J. (1999). A methodology for studying the effects of various types of prosthetic feet on the biomechanics of trans-femoral amputee gait. Journal of biomechanics, 32(9), 877-889. https://doi.org/10.1016/S0021-9290(99)00086-X

Victoria Jumilla, F. (2010). Etiquetado de carbono en las explotaciones y productos agrícolas. La iniciativa agricultura murciana como sumidero de CO2. Recuperado de https://www.google.es/ url $? \mathrm{sa}=\mathrm{t} \& \mathrm{rct}=\mathrm{j} \& \mathrm{q}=\& \mathrm{esrc}=\mathrm{s} \&$ source $=\mathrm{web} \& \mathrm{~cd}=1 \& \mathrm{ved}=0 \mathrm{ahUKEwju}$ loL63ejXAhUFshQKHUD3B AAQFggoMAA\&url=http\%3A\%2F\%2Fwww.ecorresponsabilidad.es\%2Fpdfs\%2Flibro_lessco2. pdf\&usg=AOvVaw1T3 AstaFDfoCFSwRY7w9za

Wallace, K.J. (2007). Classification of ecosystem services: problems and solutions. Biological Conservation 139, 235-246. https://doi.org/10.1016/j.biocon.2007.07.015

Wischmeyer, W., Smith, D. (1978). Predicting rainfall erosion losses - A guide to conservation planning. USA: USDA, Science and Education Administration. 